\title{
Algerian Acid Activated Clays as Efficient Catalysts for a Green Synthesis of Solketal by Chemoselective Acetalization of Glycerol with Acetone
}

\author{
Kouider Alali ${ }^{1,2, *}$, Fouad Lebsir ${ }^{2}$, Sondes Amri ${ }^{3}$, Ali Rahmouni ${ }^{1}$, Ezzedine Srasra ${ }^{3}$, \\ Néji Besbes ${ }^{3}$
}

${ }^{1}$ Laboratoire de Modélisation et de Méthodes de Calcul, Université Docteur Moulay Tahar, 20002, Saida, Algeria

${ }^{2}$ Laboratoire Chimie Physique Macromoléculaire, Département de Chimie, Faculté des Sciences Appliquées, Université Oran1 Ahmed Benbela, 31000 Oran, Algeria

${ }^{3}$ Laboratoire des Matériaux Composites et des Minéraux Argileux, Groupe de Chimie Organique Verte et Appliquée, Centre National des Recherches en Sciences des Matériaux, Technopole de Borj Cerdia, Soliman, 8027, Tunisia

Received: $28^{\text {th }}$ March 2018; Revised: $17^{\text {th }}$ October 2018; Accepted: $30^{\text {th }}$ October 2018; Available online: $25^{\text {th }}$ January 2019; Published regularly: April 2019

\begin{abstract}
The production of solketal and conversion of glycerol takes a major importance in the field of the sustainability of the biodiesel industry. The synthesis of (2,2-dimethyl-1,3-dioxolan-4-yl)methanol by the acetalization of glycerol with acetone successfully applied out using various Algerian acid activated clays $\left(\right.$ Maghnia- $\left.\mathrm{H}^{+}\right)$under autogenous pressure and without solvent. The acid catalyst clays are prepared by an easy technique by activation with the available and low-cost Maghnia clay. The purified Maghnia clay named ALC and the resulting series of acidactivated clays AL1, AL2, AL3, and AL4 are characterized by X-ray Fluorescence (XRF) investigation, $\mathrm{N}_{2}$ adorption/desorption Brunauer-Emmett-Teller (BET) surface area, X-rays Diffraction (XRD), Fourier Transform Infra Red (FT-IR) spectroscopy, SEM microscopy and the cation exchange capacity (CEC) with copper bisethylenediamine complex method, in order to study the effect of activation at the acid and the catalytic behaviour in this acetalization reaction. The results show a high catalytic activity whose that the yield of solketal production interest reached $95 \%$ at a temperature of $40{ }^{\circ} \mathrm{C}$ for a reaction time of 48 hours with full selectivity and glycerol conversion reaching up to $89 \%$. A mechanistic is proposed to explain the chemoselective of solketal production. These results indicate the potential of this Algerian acid activated clays catalysts for the acetalization of glycerol for an environmentally benign process. Copyright (C) 2019 BCREC Group. All rights reserved
\end{abstract}

Keywords: Acetalization; Acid Activated Clay; Glycerol Conversion; Solketal; Biodiesel

How to Cite: Alali, K., Lebsir, F., Amri, S., Rahmouni, A., Srasra, E., Besbes, N. (2019). Algerian Acid Activated Clays as Efficient Catalysts for a Green Synthesis of Solketal by Chemoselective Acetalization of Glycerol with Acetone. Bulletin of Chemical Reaction Engineering \& Catalysis, 14 (1): 130-141 (doi:10.9767/bcrec.14.1.2445.130141)

Permalink/DOI: https://doi.org/10.9767/bcrec.14.1.2445.130-141

\section{Introduction}

The researchers worldwide have sought to motivate the use of sustainable resources with

\footnotetext{
* Corresponding Author.

E-mail: alalikdz@yahoo.fr (K. Alali)

Telp: +213557491705, Fax: +21348374639
}

minimum pollution. Among actual solutions is to involve the production of biofuels from biomass [1]. The (2,2-dimethyl-1,3-dioxolan-4-yl) methanol, generally known by solketal, has potential to be directly applied as solvent, as plasticizer and a solubilizing in the polymer industry, suspending agent in pharmaceutical prepa- 
rations, low temperature heat-transfer fluid, surfactant and fuel additive [2,3].

Many invest to convert the glycerol into added-value products has been widely studied and several viable synthetic routes have been considered, such as hydrogenolysis [4], oxidation [5], carbonatation [6], etherification [7], esterification [8], and acetalization with either aldehydes or ketones [9-11]. The acetalization of these carbonyl compounds have usually used mineral acids catalysts like $\mathrm{HCl}$ withtriethylorthoformate and absolute ethanol [12], trialkylorthoformate and a catalytic amount of tetrabutylammonium tribromide (TBATB) in absolute alcohol [13].

These last homogeneous processes have serious practical difficulties (catalyst separation from the product stream, removal organic solvents, corrosion and environmental and economic difficulty's concerns for the effluent disposal). The reaction of acetalization of glycerol with acetone in presence of catalysts leads to a mixture of two heterocyclic, the first to five members, which is the (2,2-dimethyl-1,3dioxolan-4-yl)methanol with high selectivity, while the second to six members is 2,2 dimethyl-1,3-dioxan-5-ol [14,15] (Scheme 1).

In order to make the production of solketal easier, several works are published either using new synthetic catalysts or natural catalysts modify with different techniques like use of silica-included heteropolyacids at $70{ }^{\circ} \mathrm{C}$ and for 6 $\mathrm{h}$, conversion of glycerol and selectivity the solketal production $77 \%$ [16], mesoporus substituted silicates including Hf-TUD-1 material at $80{ }^{\circ} \mathrm{C}$ for $6 \mathrm{~h}$ in presence of dioxane and tertbutanol solvents by total selectivity of the solketal product, conversion of glycerol $<60 \%$ [17], the use of zeolite and montmollionite, whose results of yields of production of solketal and conversion of glycerol are respectively $72 \%$ yield, $73 \%$ conversion and $60 \%$ yield, $61 \%$ conversion at $40^{\circ} \mathrm{C}$ and for $1 \mathrm{~h}$ reaction time in a continuous flow reactor [18], solid catalysts based on the commercial product aluminum phosphate $\mathrm{M}-\mathrm{APO}_{4}$ modified by supported metals $\mathrm{Zr}, \mathrm{Cu}, \mathrm{Ni}$, and $\mathrm{Co}$ showed $75 \%$ of yield of production of solketal at $80^{\circ} \mathrm{C}$ and for $1 \mathrm{~h} \mathrm{[19],}$ nano-silica and molybdenum supported $\mathrm{Re}, \mathrm{Rh}$,
$\mathrm{Ru}$ or Ir nanoparticles in an inert reaction atmosphere $\left(\mathrm{N}_{2}\right)$, ultrasounds $10 \mathrm{~min}, 55^{\circ} \mathrm{C}$, and $3 \mathrm{~h}$ time reaction $93 \%$ yield, $100 \%$ conversion [20]. It is interesting to note that the most of these solid catalysts are not abundant or are very expensive with process presenting difficulties during the preparation and the application.

Beside, in our previous results, we have synthesized the 2,2-dimethyl-1,3-dioxolane from acetalization of acetone by ethylene glycol over Tunisian acid activated clays $[21,22]$ and Tunisian pillared clays [23] at $40{ }^{\circ} \mathrm{C}$, without solvent and under autogeneous pressure. In the aim of continuing the synthesis of other dioxolanes, we propose in this present work the use of Algerian clay catalyst as Maghnia clay originating from Tlemcen located in the North West Algerian region. The Algerian clay (Maghnia) is very abundant solid catalyst, low cost with simple preparation and very easy process $[24,25]$. We have studied the behavior of an easy preparation of an Algerian clays activated by hydrochloric acid for a mixture of glycerol and acetone solvent-free, without producing waste with easy separation of reagents and a important commercial product.

\section{Materials and Methods}

\subsection{Materials}

The raw clay used in this work was supplied by company "ENOF" (an Algerian Manufacture specialized in the production of non-ferric products and useful substances) located in Maghnia (North West of Algeria). Acetone and glycerol were (both > $99 \%$ ) purity; anhydrous $\left(\mathrm{MgSO}_{4} \geq\right.$ $99.5 \%)$, purity; anhydrous ( $\mathrm{NaCl} \geq 99 \%)$ and ( $\mathrm{HCl} 37 \%$ ) were procured from Sigma Aldrich.

\subsection{Preparation of Catalysts}

For this reaction, $200 \mathrm{~g}$ of Maghnia clay was used as the raw material. The fraction $<2 \mu \mathrm{m}$ was separated by sedimentation. The $<2 \mu \mathrm{m}$ fraction was purified and transformed into the sodium form with $1 \mathrm{M} \mathrm{NaCl}$ solution, The preliminary treatment of natural Maghnia clay by $1 \mathrm{M} \mathrm{NaCl}$ consists in eliminating the maximum

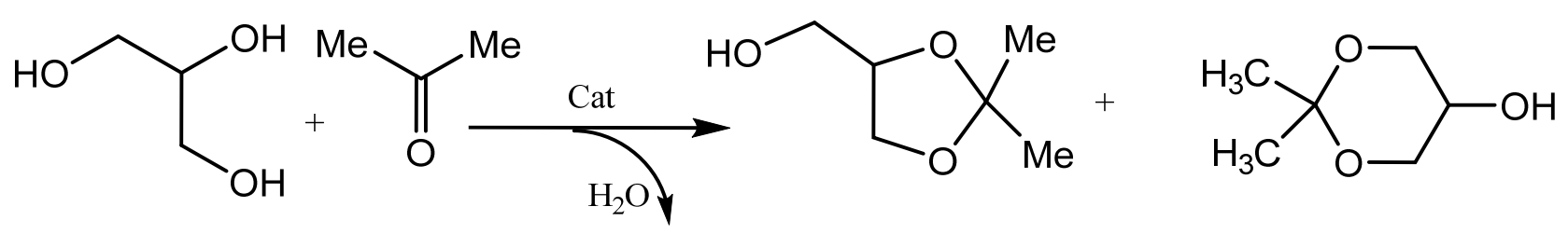

Scheme 1. Acetalization of glycerol 1 with acetone over solid catalyst 
of the crystalline phases (quartz, feldspar, calcite, etc.), replacing all the exchangeable cations of various natures by sodium cations and allowing have well-defined particle size fractions less than $2 \mu \mathrm{m}$ in size. After washing, sedimentation and dialysis, the fine sediment was freeze-dried at $60{ }^{\circ} \mathrm{C}$, the starting clay ALC is crushed in an agate mortar and sieved to obtain particles of $63 \mu \mathrm{m}$ or less.

In order to study the catalytic performances of Maghnia- $\mathrm{H}^{+}$without modifying the clay structure and catalytic performances of Maghnia- $\mathrm{H}^{+}$with modifying of the clay structure. A quantity of $20 \mathrm{~g}$ of starting clay ALC was treated with $300 \mathrm{~mL}$ of different solutions of hydrochloric acid $0.5 \mathrm{M}$ and $3 \mathrm{M}$. The mixtures were boiled at $100 \pm 2{ }^{\circ} \mathrm{C}$ in a round-bottom flask with a reflux condenser during $2 \mathrm{~h}$ and $6 \mathrm{~h}$. After these treatments, the resulting samples were washed by the distilled water until having constant $\mathrm{pH}$ and dried up at $60^{\circ} \mathrm{C}$. The product is denoted; AL1 and AL2 the activated clay treated with $0.5 \mathrm{M}$ of $\mathrm{HCl}$ and boiled during $2 \mathrm{~h}$ and $6 \mathrm{~h}$ respectively. AL3 and AL4 the activated clay treated with $3 \mathrm{M}$ of $\mathrm{HCl}$ and boiled during $2 \mathrm{~h}$ and $6 \mathrm{~h}$, respectively [26].

\subsection{Characterization Methods of Catalysts}

The different chemical elements of the starting clay ALC and the acid activated clays; AL1, AL2, AL3, and AL4 were transformed into oxides and analyzed by PANalytical-Zetium diffractometers and spectrometers XRF analyzer with SumXcore technology, SDD detector, Power upgrades ranging from 1 to $2.4,3$ or 4 $\mathrm{kW}$ to enhance sensitivity and Analysis Diameter: $6 \mathrm{~mm}$ to $37 \mathrm{~mm}$. XRD patterns of deferent's clays materials were collected on a "Panalylitical X'Pert High-Score Plus" diffractometer using $\mathrm{Cu}-\mathrm{K}_{\mathrm{a}}$ sealed-tube radiation source $(k=1.54178 \AA)$. Diffraction data were obtained in the range from $2^{\circ}$ to $80^{\circ}$. The IR spectra of catalysts were collected with a Nicolet spectrophotometer model 560, with a scanning range between 400 and $4000 \mathrm{~cm}^{-1}$ and spectra resolution $0.35 \mathrm{~cm}^{-1}$, Samples were prepared as tablets diluted in $\mathrm{KBr}$, keeping constant the sample/KBr (1\%) ratio and the total weight of sample.

The images SEM obtained by scanning electron microscopy of the samples using with Max. 60,000x Magnification, Multi mode (SE and BSE) Detector, resolution of a $20 \mathrm{~nm}$ and $5 \mathrm{kV}$ to $30 \mathrm{kV}$ Variable Accelerating Voltage. Small amounts of powdered clays were supported on a double-sided adhesive carbon and then blown with a pear to remove anything that is not fixed. The carbon lakes are introduced in the Hirox SH $4000 \mathrm{M}$ analyzer type. $\mathrm{N}_{2}$ adsorptiondesorption experiments were carried out at 77 $\mathrm{K}$ on Quantachrome. The adsorption/desorption isotherms were used to determine the specific surface areas (SA) using the BET equation. The microspore volume was determined using the $t$-plot method and the total pore volume of the samples $V_{t}$, was calculated at $P / P_{0}=0.99$. Before each measurement the samples were out gassed for $2 \mathrm{~h}$ at $130{ }^{\circ} \mathrm{C}$. Cations exchange capacity (CEC) measurement values were determined using the copper ethylendiamine $\left((\mathrm{EDA})_{2} \mathrm{CuCl}_{2}\right)$ complex method [27].

\subsection{Acetalization of Glycerol 1 with Acetone 2}

For this reaction $2.3 \mathrm{~g}(25 \mathrm{mmol})$ of glycerol $1,5.8 \mathrm{~g}(100 \mathrm{mmol})$ of acetone 2 with a $1: 4 \mathrm{ra}$ tio molar and $0.1 \mathrm{~g}$ of acid activated clay were placed in an autoclave at $40{ }^{\circ} \mathrm{C}$ under autogeneous pressure and without solvent during different times of reaction. The resulting reaction mixture after the reaction time is dried by adding $50 \mathrm{mg}$ of an anhydrous $\mathrm{MgSO}_{4}$. Then, the reaction organic mixture and the solid catalysts were separated by centrifugation. The product was identified by ${ }^{1} \mathrm{HNMR}$ and ${ }^{13} \mathrm{CNMR}$ spectral analysis $[9,21,23]$. For ${ }^{1} \mathrm{HNMR}$ and ${ }^{13} \mathrm{CNMR}$ studies, different spectra were respectively recorded at 400 and $75 \mathrm{MHz}$ Bruker AM 300 spectrometer. Temperature was fixed at 25 ${ }^{\circ} \mathrm{C}$ using a Bruker VT1000 variable temperature control unit, measured by calibrated Pt100 resistance thermometer. The chemical shifts are given in ppm with respect to external TMS reference at $0 \mathrm{ppm}$.

\section{Result and Discussion}

\subsection{Characterization of the Catalysts}

$\mathrm{XRF}$ analysis shows that activation with hydrochloric acid of $0.5 \mathrm{M}$ the starting clay ALC, whereas activation with hydrochloric acid of 3 $\mathrm{M}$ affects the texture of the clay by dissolving the aluminium. These results are indicated by the levels of alumina $\mathrm{Al}_{2} \mathrm{O}_{3}$ which are $18.481 \%$ and $18.593 \%$ in the AL1 and AL2 catalysts, respectively and the decrease in the alumina levels in AL3 and AL4 of $13.851 \%$ and $8.570 \%$, respectively. Besides, the levels of silica $\mathrm{SiO}_{2}$ which are $56.642 \%$ and $59.338 \%$ in the AL1 and AL2 catalysts, respectively and the increase in the silica levels in AL3 and AL4 of $66.401 \%$ and $77.207 \%$, respectively. On the other hand, the significant decreases of $\mathrm{Na}_{2} \mathrm{O}$ and $\mathrm{CaO}$ after acid activation indicates, that it 
is a transformation from a $\mathrm{Ca} / \mathrm{Na}$-clay to and $\mathrm{H}$-acidic clay (Table 1).

The effect of the activation with hydrochloric acid of $0.5 \mathrm{M}$ and $3 \mathrm{M}$ is also expressed as a function of the destroy of the octahedron layer of the catalyst clays is calculated with (1) $[26,28,29]$ and presented in the histogram (Figure 1). Six hours of activation destroys $61 \%$ of the octahedral layers (Table 2). Acid activation progressively destroys the starting clay ALC structure, leaving only relics of the original mineral and amorphous silica.

Octahedron Sheet destroy $(\%)=$ $\frac{M\left(\mathrm{Al}_{2} \mathrm{O}_{3}+\mathrm{Fe}_{2} \mathrm{O}_{3}+\mathrm{MgO}\right) \mathrm{ALC}-\mathrm{M}\left(\mathrm{Al}_{2} \mathrm{O}_{3}+\mathrm{Fe}_{2} \mathrm{O}_{3}+\mathrm{MgO}\right) \mathrm{ALi}}{\mathrm{M}\left(\mathrm{Al}_{2} \mathrm{O}_{3}+\mathrm{Fe}_{2} \mathrm{O}_{3}+\mathrm{MgO}\right) \mathrm{ALC}} \times 100$

where, $M\left(\mathrm{Al}_{2} \mathrm{O}_{3}+\mathrm{Fe}_{2} \mathrm{O}_{3}+\mathrm{MgO}\right)_{\mathrm{ALC}}$ is amount (\%) of octahedron sheet in the starting clay ALC, $M$ $\left(\mathrm{Al}_{2} \mathrm{O}_{3}+\mathrm{Fe}_{2} \mathrm{O}_{3}+\mathrm{MgO}\right)_{\text {Ali }}$ is amount (\%) of octahedron sheet in the acid activated clay $i=1,2,3,4$.

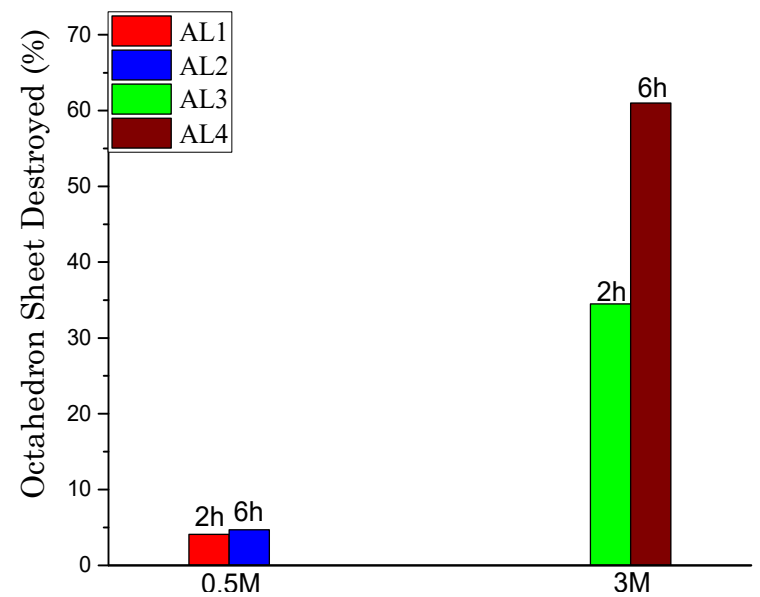

$\mathrm{HCl}$ Concentration (mol.L-1) Acid Activation of Catalyst Clay

Figure 1. Octahedron layer destroy according to the concentration of $\mathrm{HCl}$ and the activation time
The extracted amounts of iron, magnesium and aluminium are calculated with (2) $[26,28,29]$ and represented in (Table 3).

Amount of extracted of metal oxide (\%) = $\frac{N(\text { metal oxide }) A L C-N(\text { metal oxide }) A L i}{N(\text { metal oxide }) A L C} \times 100$

where, $N$ (oxide of metal) ALC $_{\text {is amount }}$ (\%) of metal oxide in the starting clay ALC; $N$ (oxide of metal) $)_{\text {Ali }}$ is amount (\%) of metal oxide in the activated clay $i=1,2,3$, and 4 .

X-ray diffraction patterns of the studied samples before and after acid treatment are reported in Figure 2. Clearly shows (001) peak the basal reflection appeared at $13.09 \AA$ of starting clay sample shift progressively and reaches $15.05 \AA$ indicating the transformation of calcic smectite to his acidic form for treated catalysts AL1, AL2, and AL3. While the nearly total disappearance of the basal reflection $14.463 \AA$ and the appearance of halo in AL4 sample indicate the destruction of clay structure. The reflections at $4.258 \AA$ and 3.328 $\AA$ indicate the presence of quartz in all samples [26,29].

On the other hand, the Infrared analysis of the different catalysts is represented in Figure 3 . The frequencies observed near at $3433 \mathrm{~cm}^{-1}$ for the instance the $\mathrm{OH}$ stretching of the hydration water and $1630 \mathrm{~cm}^{-1}$ were band and the deformation band of the $\mathrm{O}-\mathrm{H}$ bond. The intense bands near $1042 \mathrm{~cm}^{-1}$ are those of the $\mathrm{Si}-\mathrm{O}$ stretching frequencies in al catalysts clays. The presence of $\mathrm{SiO}_{2}$ of quartz in different catalysts is indicated by the band at 797 $\mathrm{cm}^{-1}$. The frequencies towards $3620 \mathrm{~cm}^{-1}$ and $917 \mathrm{~cm}^{-1}$ which weaken under the effect of the treatment by the acid activation in the order ALC, AL1, AL2, AL3, and AL4 indicates the presence of $\mathrm{Al}-\mathrm{Al}-\mathrm{OH}$ bonds. This can be considered as characteristic of a octahedral clay

Table 1. Elementary compositions of starting clay ALC and its acid activated clays AL1, AL2, AL3, and AL4

\begin{tabular}{cccccccccc}
\hline \multirow{2}{*}{ Species } & \multicolumn{7}{c}{ Composition wt\% } \\
\cline { 2 - 8 } & $\mathrm{SiO}_{2}$ & $\mathrm{Al}_{2} \mathrm{O}_{3}$ & $\mathrm{Fe}_{2} \mathrm{O}_{3}$ & $\mathrm{MgO}$ & $\mathrm{CaO}$ & $\mathrm{Na}_{2} \mathrm{O}$ & $\mathrm{K}_{2} \mathrm{O}$ & $\mathrm{SO}_{3}$ & L.O.I. \\
\hline $\mathrm{ALC}$ & 53.576 & 18.846 & 2.429 & 3.540 & 0.563 & 1.584 & 0.813 & 0.431 & 17.990 \\
$\mathrm{AL} 1$ & 56.642 & 18.481 & 2.227 & 2.976 & 0.240 & 0.817 & 0.874 & 0.012 & 17.080 \\
$\mathrm{AL} 2$ & 59.338 & 18.593 & 2.134 & 2.827 & 0.167 & 0.689 & 0.877 & 0.008 & 11.790 \\
$\mathrm{AL} 3$ & 66.401 & 13.851 & 1.087 & 1.287 & 0.089 & 0.695 & 0.895 & 0.001 & 14.500 \\
$\mathrm{AL} 4$ & 77.207 & 8.570 & 0.693 & 0.365 & 0.080 & 0.666 & 0.887 & 0.053 & 10.650 \\
\hline
\end{tabular}

L.O.I.: Loss on ignition at $900 \circ \mathrm{C}$ in $\mathrm{wt} \%$ 
[26,29-31]. The results of scanning electron microscopy SEM analysis images of samples was obtained and presented with the same enlarging equal to $2000 \times$ show the impact of the acid activation on the clay AL4. This is the most affected with the smallest size grains are presented in Figure 4.

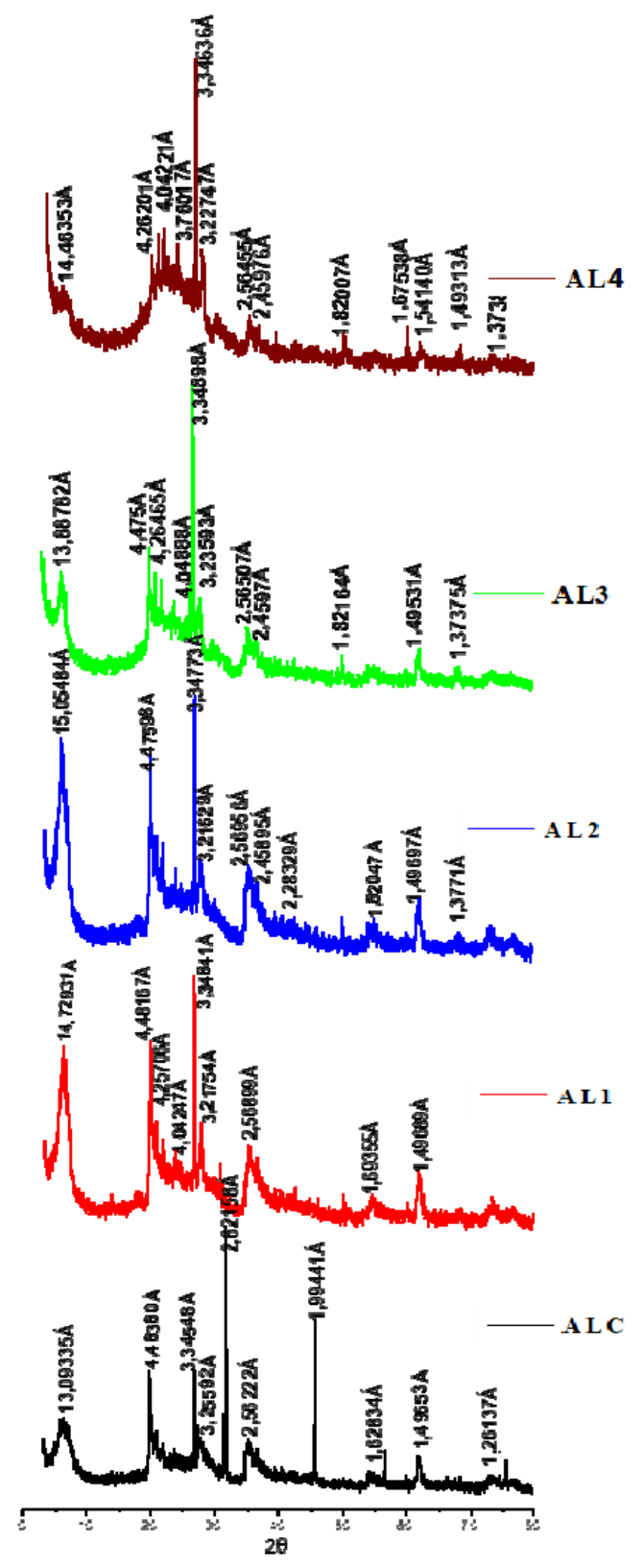

Figure 2. X-ray diffractograms of starting clay ALC and its acid activated clays AL1, AL2, AL3, AL4
Nitrogen adsorption-desorption isotherms before and after acid activation of starting clay are shown in Figure 5. The curves are of type II of BDDT classification [32]. The starting clay and the acid activated clays clearly present H3 hysteresis type, by identification with the clas-

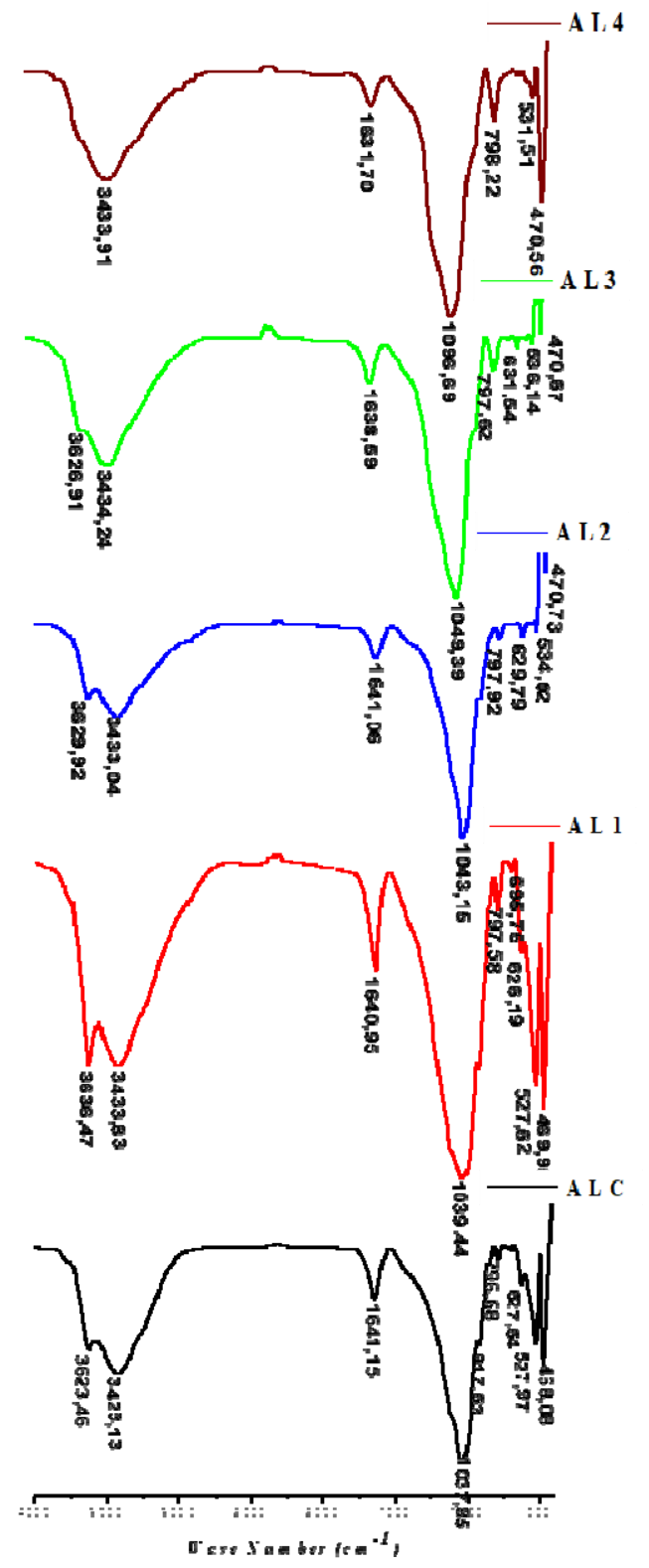

Figure 3. FT-IR spectra of starting clay ALC and its acid activated clays AL1, AL2, AL3, AL4

Table 2. Octahedron sheet destroy after acid activation of starting clay ALC

\begin{tabular}{lcccccc}
\hline \multicolumn{1}{c}{ Concentration of the activating acid HCl (mol.L-1) } & \multicolumn{2}{c}{$0.5 \mathrm{M}$} & & \multicolumn{2}{c}{$3 \mathrm{M}$} \\
\cline { 1 - 2 } \cline { 5 - 7 } Time of acid activation (hour) & 2 & 6 & & & 6 \\
Catalyst clay & & AL1 & AL2 & & AL3 & AL4 \\
Amount of octahedron sheet or layer destroy(\%) & 4.2 & 4.7 & & 34.5 & 61 \\
\hline
\end{tabular}


sification of the UIPAC [33]. Figure 6 shows the textural parameters of surface for activated and non-activated clay. An imported increase is observed in the specific surface area $\mathrm{S}_{\text {BET }}$ and the external surface $\mathrm{S}_{\text {Ext }}$ under the effect the
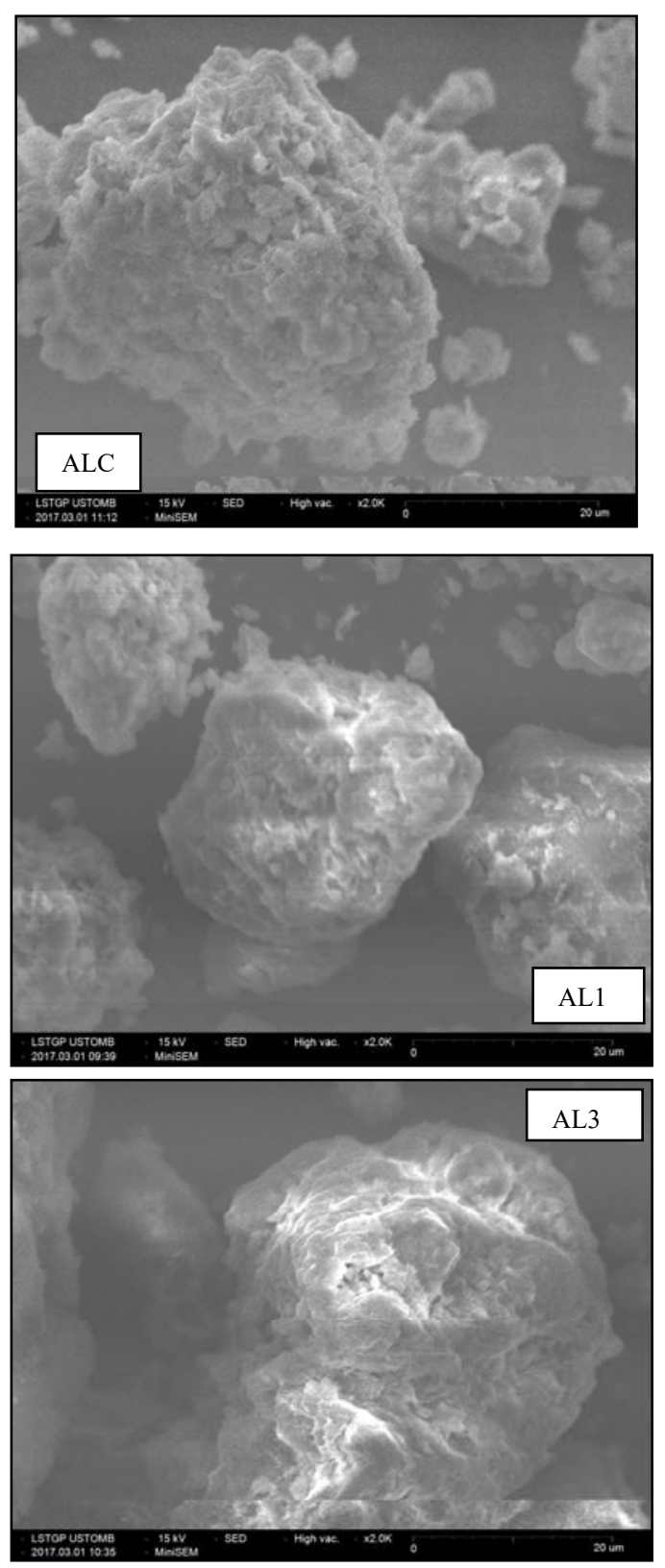

acid activation. A maximum of $\mathrm{S}_{\text {BET }}\left(233 \mathrm{~m}^{2} / \mathrm{g}\right)$ and $\mathrm{S}_{\text {Ext }}\left(214 \mathrm{~m}^{2} / \mathrm{g}\right)$ are reached for AL3 (Table 4). A slight increase is observed of the total specific surface area with a maximum reached (35 $\mathrm{m}^{2} / \mathrm{g}$ ) for AL2. The cation exchange capacities (CEC) decrease after modification by indicating the impact of the activation of the acid on cations interlayer (Table 4).

\subsection{Catalytic Performance Studies}

The spectra analysis of 1 HNMR and ${ }^{13} \mathrm{CNMR}$ shown that the condensation of glycerol 1 with acetone 2 catalyzed by the starting clay ALC gives no product whatever the time of contact and there is only one product of the reaction of acetalization of glycerol 1 with acetone 2 catalyzed by acid activated clays AL1, AL2, AL3 and AL4. It interesting to notice that
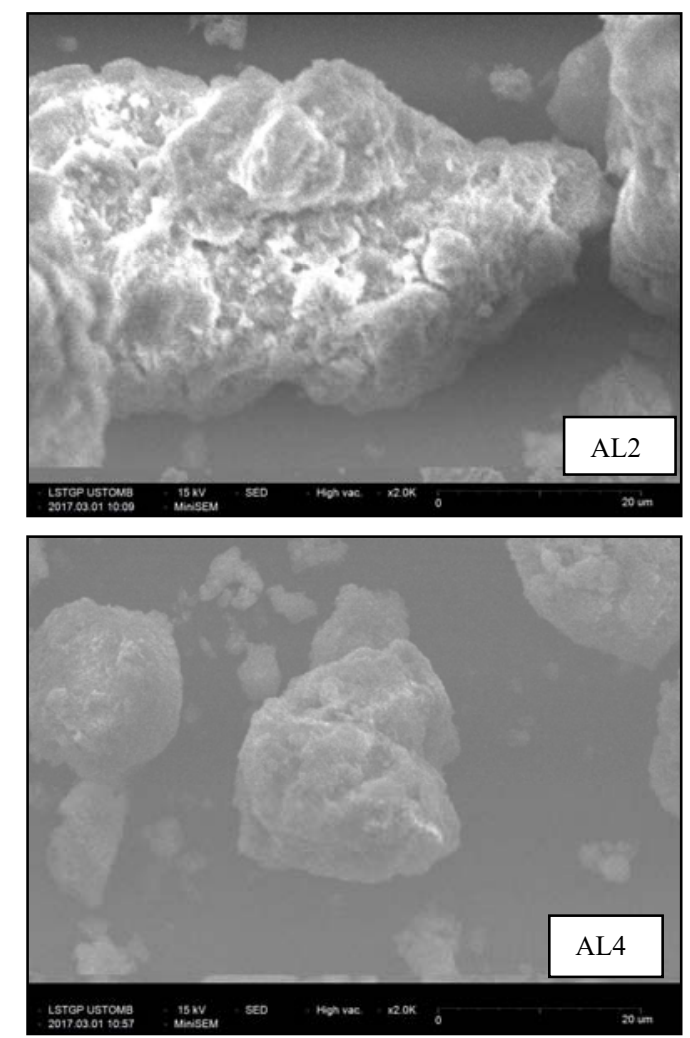

Figure 4. Images MEB of deferent's clays catalyst the starting ALC and its acid activated clays AL1, AL2, AL3, AL4

Table 3. Amount (\%) of extracted oxides of iron, magnesium and aluminium from the clay after acid activation of starting clay ALC

\begin{tabular}{|c|c|c|c|c|}
\hline \multirow{2}{*}{$\frac{\text { Concentration of the activating acid } \mathrm{HCl}\left(\mathrm{mol}^{\left.-\mathrm{L}^{-1}\right)}\right.}{\text { Time of acid activation (hour) }}$} & \multicolumn{2}{|c|}{$0.5 \mathrm{M}$} & \multicolumn{2}{|c|}{$3 \mathrm{M}$} \\
\hline & 2 & 6 & 2 & 6 \\
\hline Catalyst clay & AL1 & AL2 & AL3 & AL4 \\
\hline Amount of extracted of $\mathrm{Al}_{2} \mathrm{O}_{3}(\%)$ & 1.94 & 1.34 & 26.50 & 54.53 \\
\hline Amount of extracted of $\mathrm{Fe}_{2} \mathrm{O}_{3}(\%)$ & 8.32 & 16.26 & 55.25 & 71.47 \\
\hline Amount of extracted of $\mathrm{MgO}(\%)$ & 15.73 & 20.14 & 63.64 & 89.69 \\
\hline
\end{tabular}


the same results were obtained with complete selectivity of solketal 3 [9,17-19] (Scheme 2). Figure 7 presents four spectra of $\mathrm{NMR}{ }^{13} \mathrm{C}$. the spectrum (a) present a spectra of $\mathrm{NMR}{ }^{13} \mathrm{C}$ with chemicals shifts carbons of the reagents of glycerol $1 ; \delta=71.569$ ppm $\left(\mathrm{CH}_{2}-\mathrm{CH}(\mathrm{OH})-\mathrm{CH}_{2}\right)$, $\delta=62.344 \mathrm{ppm}$ and $62.132 \mathrm{ppm}\left(2\left(\mathrm{CH}_{2}-\mathrm{OH}\right)\right)$ and acetone $2 ; \delta=29.8 \mathrm{ppm} \quad\left(\mathrm{CO}\left(\underline{\mathrm{CH}}_{3}\right)_{2}\right)$, $\delta=205.96 \mathrm{ppm}(\underline{\mathrm{C}}=\mathrm{O})$ and the only product called solketal 3; $\delta=108.43$ ppm $(\mathrm{O}-\underline{\mathrm{C}}-\mathrm{O}), \delta=75.6$ ppm $\left(\mathrm{O}-\underline{\mathrm{CH}}-\mathrm{CH}_{2}-\mathrm{OH}\right), \delta=65.4 \mathrm{ppm}\left(\mathrm{CH}-\underline{\mathrm{CH}}{ }_{2}-\mathrm{O}\right)$, $\delta=63.175 \mathrm{ppm} \quad\left(\mathrm{HO}-\underline{\mathrm{CH}}_{2}-\mathrm{CH}\right), \quad \delta=25.91 \mathrm{ppm}$

Table 4. Results of surfaces area BET (SBET), Total specific surface area $\left(\mathrm{S}_{\mathrm{t}}\right)$, External specific surface ( $\mathrm{S}_{\text {Exter }}$ ) and cation exchange capacities (CEC) of starting clay ALC and its acid activated clays AL1, AL2, AL3, AL4

\begin{tabular}{lccccc}
\hline Catalysts & ALC & AL1 & AL2 & AL3 & AL4 \\
\hline S $_{\text {BET }}\left(\mathrm{m}^{2} / \mathrm{g}\right)$ & 7 & 79 & 157 & 233 & 197 \\
$\mathrm{~S}_{\text {Exter }}\left(\mathrm{m}^{2} / \mathrm{g}\right)$ & - & 52 & 122 & 214 & 167 \\
$\mathrm{~S}_{\mathrm{t}-}\left(\mathrm{m}^{2} / \mathrm{g}\right)$ & 7 & 27 & 35 & 19 & 29 \\
$\begin{array}{c}\mathrm{CEC} \\
\left(\mathrm{m}_{\mathrm{eq}} / 100 \mathrm{~g}\right)\end{array}$ & 70 & 48 & 39 & 36 & 21 \\
\hline
\end{tabular}

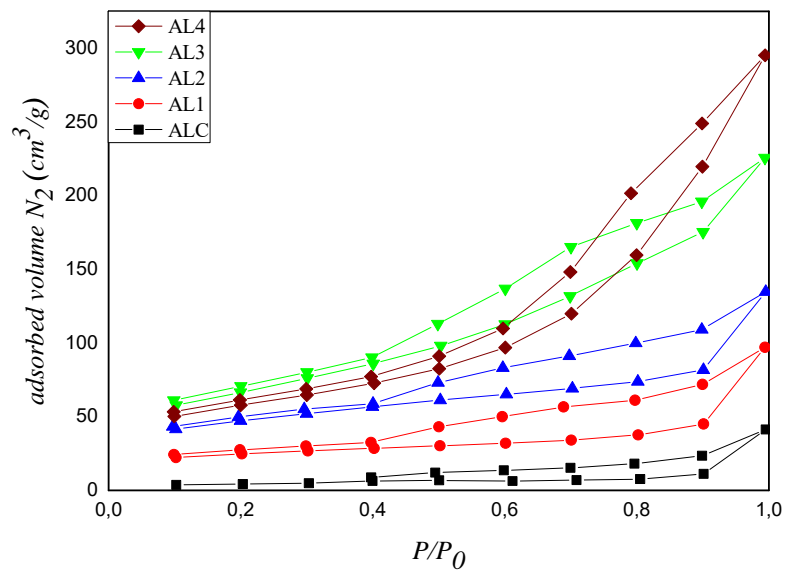

Figure 5. Nitrogen adsorption-desorption isotherms of starting clay ALC and its acid activated clays AL1, AL2, AL3, AL4
$\left(\mathrm{C}-\underline{\mathrm{C}}_{\text {trans }} \mathrm{H}_{3}\right)$ and $\delta=24.5 \mathrm{ppm}\left(\mathrm{C}-\underline{\mathrm{C}}_{\text {cis }} \mathrm{H}_{3}\right)$. The peaks $77.13 \mathrm{ppm}, 76.71 \mathrm{ppm}$ and $76.66 \mathrm{ppm}$ in NMR ${ }^{13} \mathrm{C}$ spectra are the chemical shifts of the deuterated solvent $\mathrm{CDCl}_{3}$ of NMR analysis, spectra (b) of the pure (2,2-dimethyl-1,3dioxolan-4-yl)-methanol, spectra (c) of the pure glycerol and (d) spectra of the pure acetone. Figure 8 presents four NMR ${ }^{1} \mathrm{H}$ Spectra; (e) spectra of acetalization reaction with chemicals shifts protons of reagents glycerol $1 ; \delta=4.49$ ppm ( $\left.\underline{\mathrm{HO}}-\mathrm{CH}_{2}-\mathrm{CH}(\mathrm{O} \underline{\mathrm{H}})-\mathrm{CH}_{2}-\mathrm{O} \underline{\mathrm{H}}\right), \delta=3.17 \mathrm{ppm}$ $\left(\mathrm{CH}_{2}-\mathrm{CH}(\mathrm{OH})-\mathrm{CH}_{2}\right) \delta=3.00 \mathrm{ppm}\left(\mathrm{CH}_{2}-\mathrm{CH}(\mathrm{OH})-\right.$ $\left.\mathrm{CH}_{2}\right)$, acetone $2 ; \delta=1.97 \mathrm{ppm}\left(\mathrm{CO}\left(\underline{\mathrm{CH}}_{3}\right)_{2}\right)$ and the product (2,2-dimethyl-1,3-dioxolan-4-yl)methanol called solketal $3 ; \delta=4$ ppm (O-Cㅍ$\left.\mathrm{CH}_{2}-\mathrm{OH}\right), \delta=3.42 \mathrm{ppm}\left(\mathrm{O}-\mathrm{CH}-\mathrm{CH}_{2}-\mathrm{OH}\right), \delta=2.47$ ppm (O-CH-CH $2-\mathrm{OH}), \quad \delta=3.82$ ppm (O$\left.\underline{\mathrm{H}}_{\text {cis }} \mathrm{CH}_{\text {trans }}-\mathrm{CH}-\right), \quad \delta=3.56 \mathrm{ppm} \quad\left(\mathrm{O}-\mathrm{H}_{\text {cis }} \underline{\mathrm{CH}}_{\underline{\text { trans }}^{-}}\right.$ $\mathrm{CH}-), \delta=1.17 \mathrm{ppm}\left(\mathrm{CH}_{3}\right)_{2}$, (f) spectra of the pure (2,2-dimethyl-1,3-dioxolan-4-yl)-methanol, (g) spectra of the pure glycerol, (h) spectra of the pure acetone. However, other works have shown that this acetalization reaction results in a mixture of two products, the solketal molecule (2,2-dimethyl-1,3-dioxolan-4-yl)-methanol, a five membered ring and the 2,2-dimethyl-1,3dioxan-5-ol, a six membered ring [14,15] (Scheme 1).

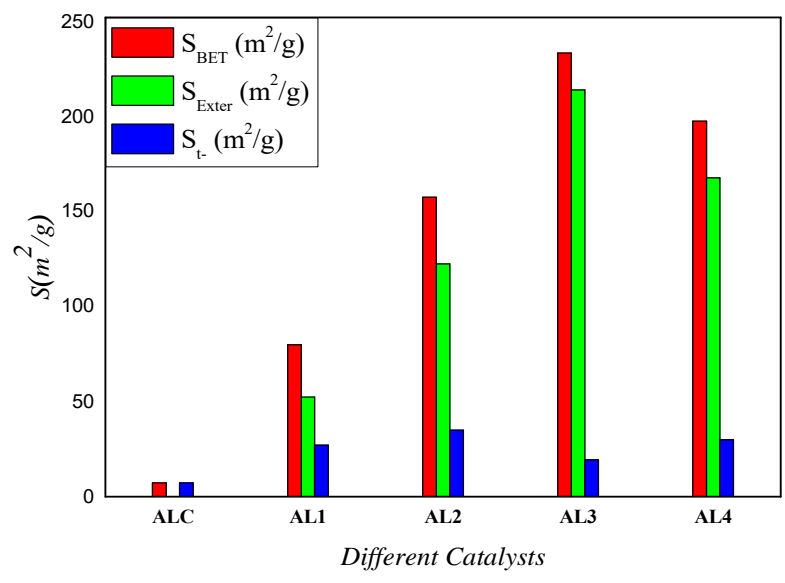

Figure 6. Evolution of Surfaces area $\operatorname{BET}\left(\mathrm{S}_{\mathrm{BET}}\right)$, Total specific surface area $\left(\mathrm{S}_{\mathrm{t}}\right)$ and External specific surface ( $\mathrm{S}_{\text {Exter }}$ ) of starting clay ALC and its acid activated clays AL1, AL2, AL3, AL4

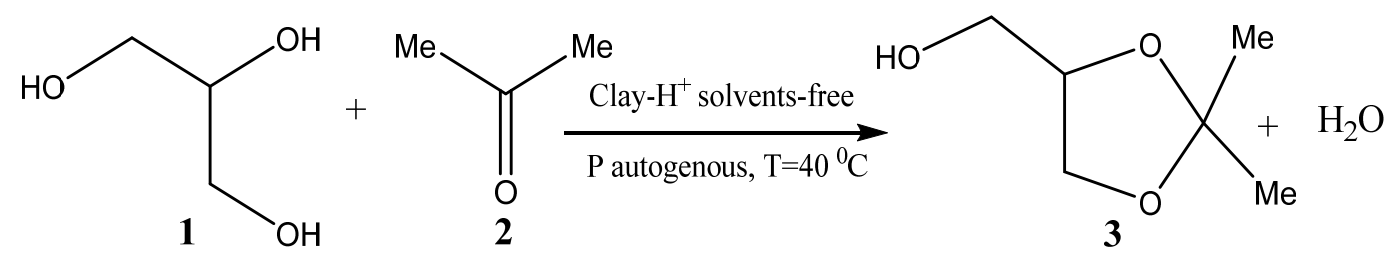

Scheme 2. Acetalization of glycerol 1 with acetone 2 catalized by maghnite- $\mathrm{H}^{+}$clays 
The yield (\%) of produced solketal, conversion (\%) of glycerol of the reaction is calculated with Equations (3) and (4).

(3)

yield $(\%)=\left(\frac{\text { moles of produced solketal }}{\text { initial moles of glycerol }}\right) \times 100$

glycerol conversion $(\%)=$

(initial moles of glycerol - remaining moles of glycerol ) $x 100$ initial moles of glycerol

The acid activation with $0.5 \mathrm{M}$ of $\mathrm{HCl}$ is now better than the acid activation with $3 \mathrm{M}$ of $\mathrm{HCl}$. Figure 9 presents the evolution of yield of solketal 3 with different solid heterogeneous catalysts as a function of time at a temperature of $40{ }^{\circ} \mathrm{C}, 0.1 \mathrm{~g}$ of catalyst and molar ration $1: 4$ Glycerol:Acetone. Figure 10 shows also the results of the conversion of the glycerol whose maximum conversion is $89 \%$ with the activated clay AL1 after $3 \mathrm{~h}$ of reaction time. The conversion of glycerol 1 decreases with the longest reaction time for all acid activated clays AL1, AL2, AL3, and AL4. Figure 11 shows the difference in the catalytic performance of these last five Algerian clays at the temperature of $40{ }^{\circ} \mathrm{C}$ and $48 \mathrm{~h}$ reaction time. This catalytic activity which reaches $95 \%$ of production yield of the solketal 3 catalyzed by AL1 and which decreases according to conditions of preparation of the acid activated clays with hydrochloric acid $86 \%, 67 \%$, and $54 \%$, respectively AL2, AL3 and AL4 and no reaction with ALC.
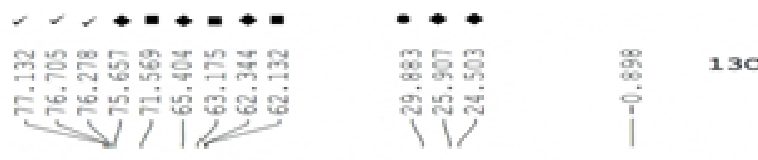

Solketal

a

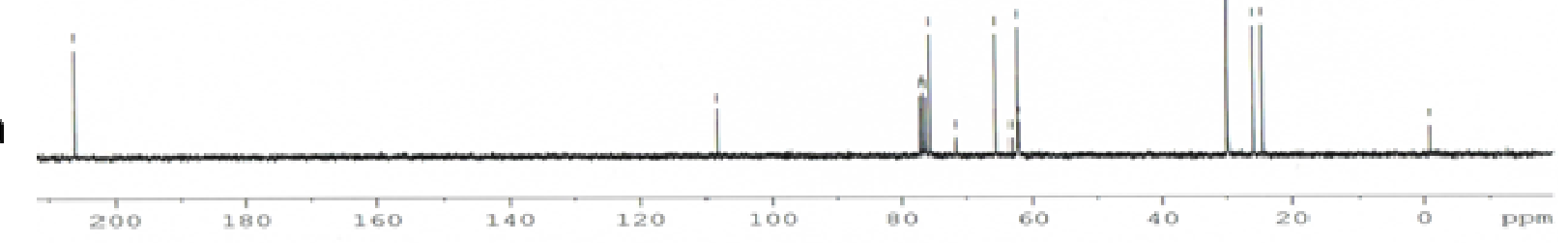

b
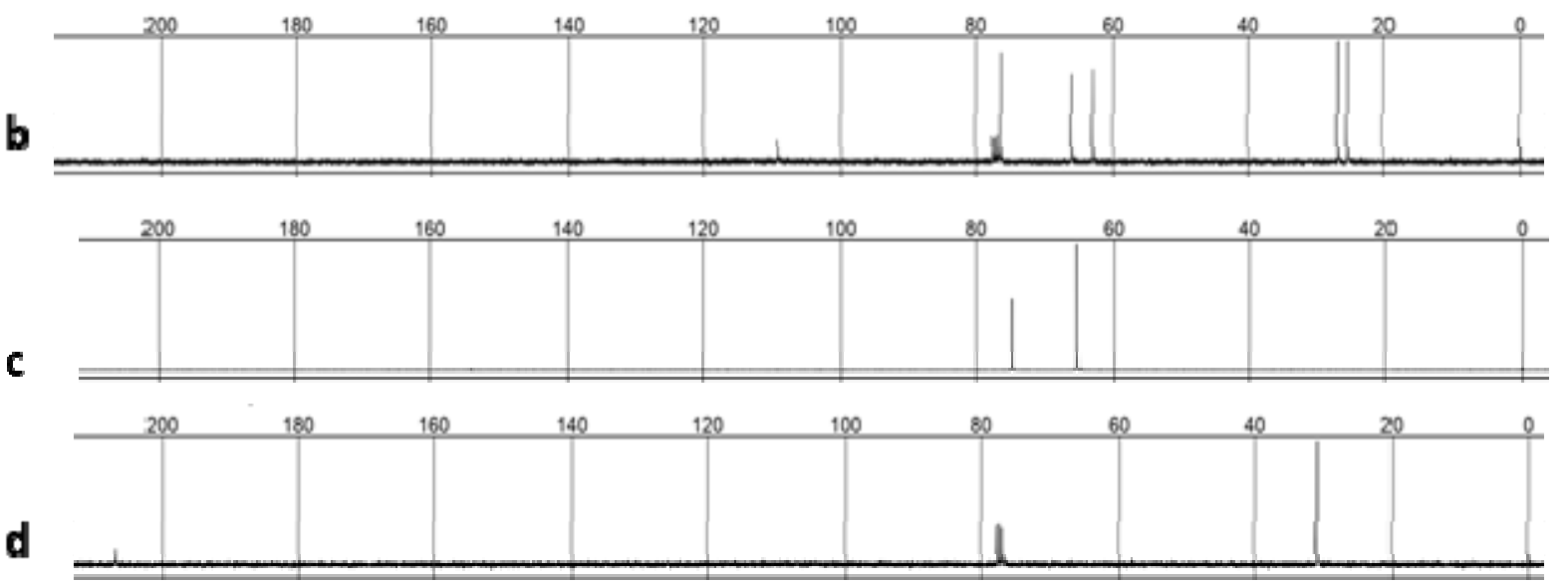

Figure 7. NMR 13C Spectra ; (a) of acetalization reaction of reagents glycerol 1, acetone 2 and the product (2,2-dimethyl-1,3-dioxolan-4-yl)-methanol called solketal 3, (b) spectra of the pure (2,2dimethyl-1,3-dioxolan-4-yl)-methanol, (c) spectra of the pure glycerol, (d) spectra of the pure acetone 


\subsection{Reaction Mechanism}

Several experimental works are proposing different mechanisms for the acetalization reaction of glycerol 1 with acetone 2 [17], but do not explain the high selectivity of production of the 5-membered heterocycle 3 . In this study a new mechanism is proposed in order to explain the selectivity of synthesis of the solketal 3 in the acetalization reaction in the presence of heterogeneous catalysts (Scheme 3). The theoretical study on the selectivity of the solketal product with a 5-atom ring for the same acetalization reaction of glycerol with acetone using benzensulfonic acid supported as a solid catalyst [34], supports the proposed mechanism with the following important steps:

Step 1; the interaction reaction of the two reagents glycerol 1 and acetone 2 on the surface of the catalyst.

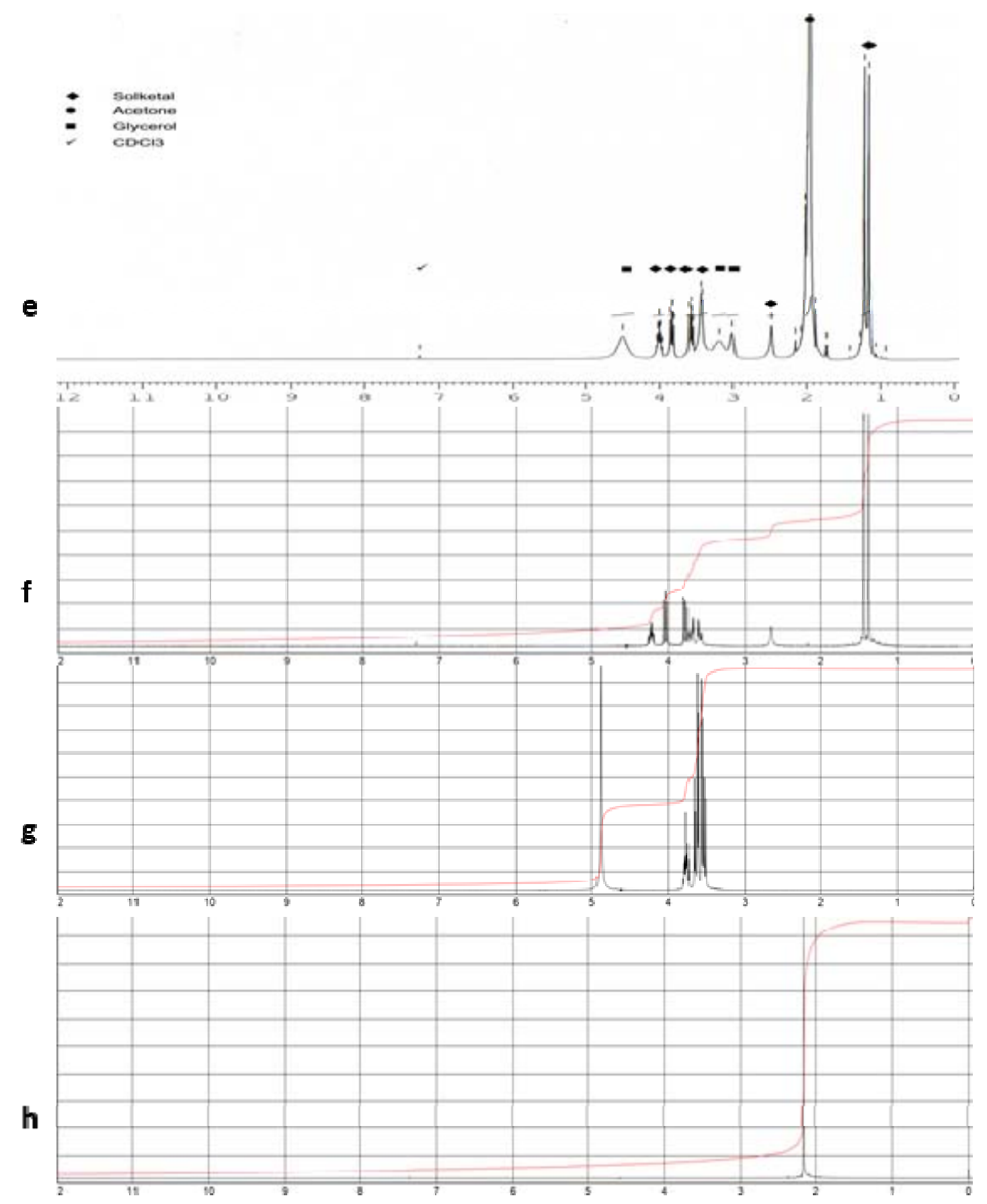

Figure 8. NMR 1H Spectra ; (e) of acetalization reaction of reagents glycerol 1 , acetone 2 and the product (2,2-dimethyl-1,3-dioxolan-4-yl)-methanol called solketal 3, (f) spectra of the pure (2,2-dimethyl-1,3-dioxolan-4-yl)-methanol, (g) spectra of the pure glycerol, (h) spectra of the pure acetone 


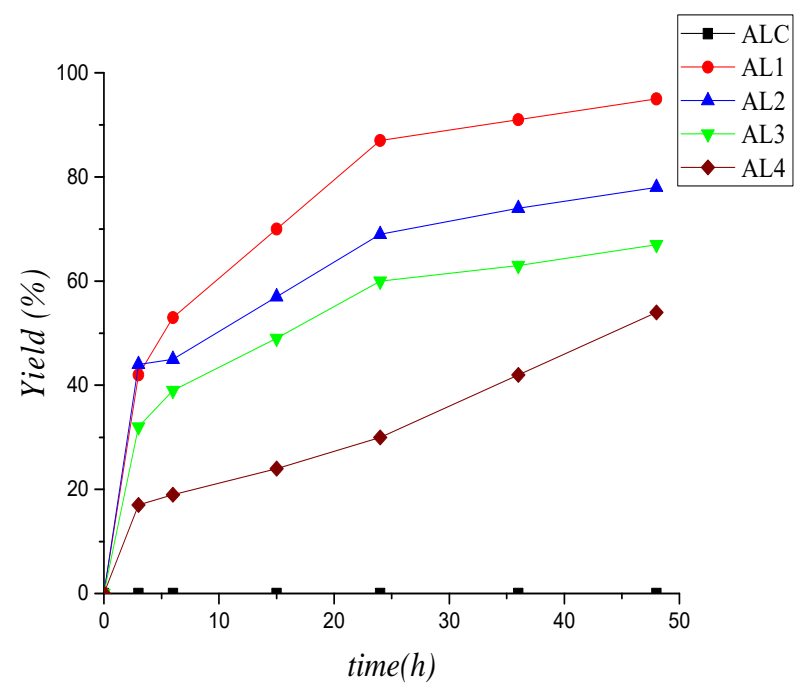

Figure 9. Yield of production of solketal 3 different catalysts ALC, AL1, AL2, AL3 and AL4 as a function of time at $\mathrm{T}=40^{\circ} \mathrm{C}, 0.1 \mathrm{~g}$ of catalyst and molar ration 1:4 Glycerol : Acetone

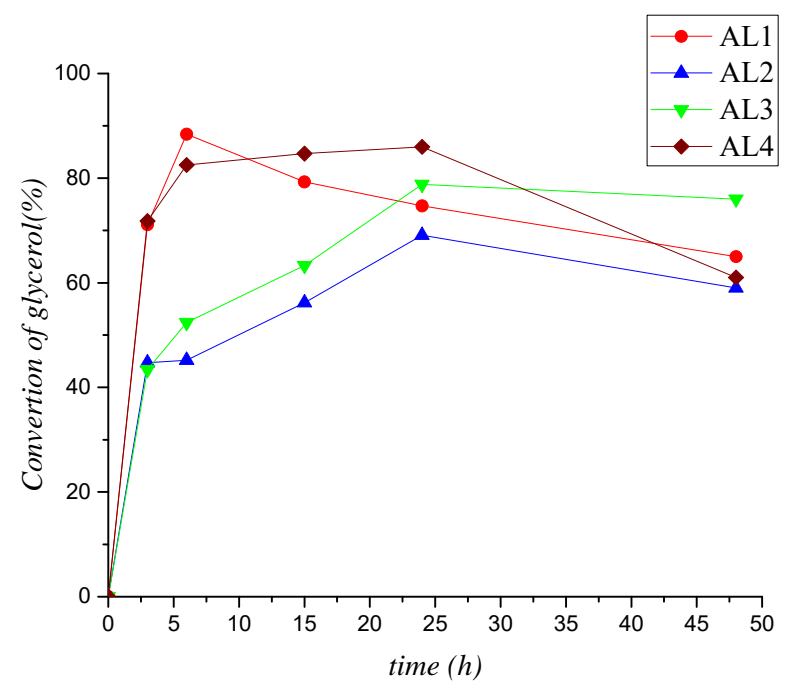

Figure 10. Amount (\%) of the conversion of glycerol 1 in the acetalization reaction with acetone 2 catalyzed by AL1, AL2, AL3, and AL4 as a function of time at $\mathrm{T}=40{ }^{\circ} \mathrm{C}, 0.1 \mathrm{~g}$ of catalyst and molar ration 1:4 Glycerol:Acetone
Step 2; the reaction between these two reagents 1 and 2 on the surface of the catalyst to form the hemi-acetal and the cyclization reaction by an $\mathrm{SN}_{2}$ nucleophilic substitution mechanism with the oxygen closest to the second glycerol 1 reagent, which promotes the formation of the 5-membered ring the solketal and water.

Step 3; the formation of solketal 3 and departure of water.

\section{Conclusions}

The results of the physicochemical characterizations of the catalyst show that the longer the activation time and the higher the $\mathrm{HCl}$ concentration, the clay loses its structural morphology is converged to an amorphous state by dissolution of aluminum, iron and magnesium form the octahedron sheet. In the same context, it was observed that the activity of the

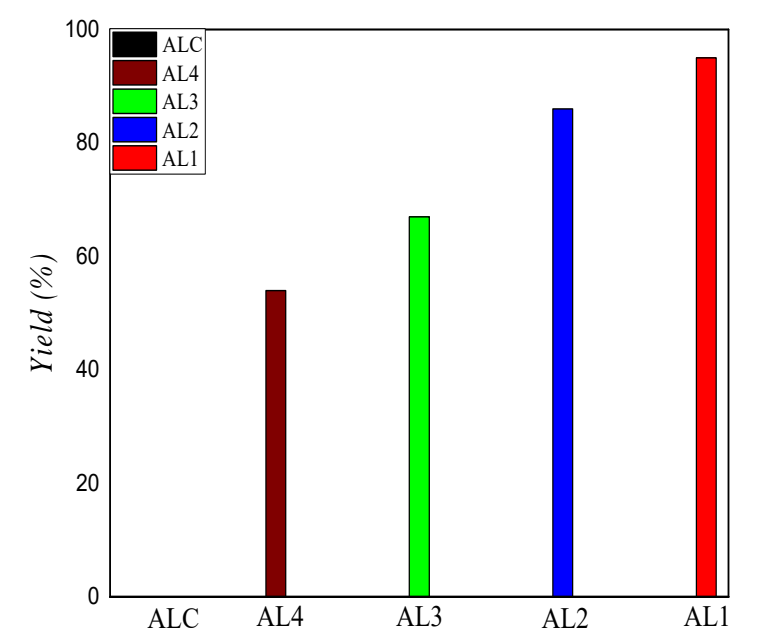

Starting clay ALC and acid activated clays AL1,AL2, AL3 and AL4

Figure 11. Yield of acetalization of glycerol 1 with acetone 2 for different catalysts ALC, AL1, AL2, AL3 and AL4 at $48 \mathrm{~h}$ and at the temperature of $\mathrm{T}=40{ }^{\circ} \mathrm{C} 0.1 \mathrm{~g}$ of catalyst and molar ration 1:4 Glycerol:Acetone

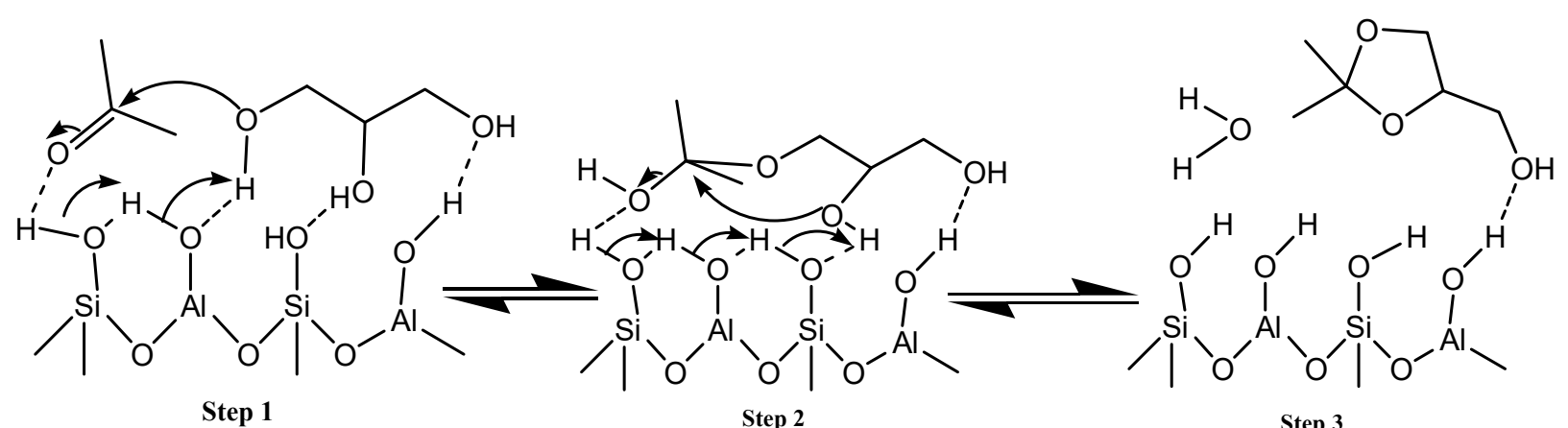

Scheme 3. Mechanism proposed for acetalization reaction of glycerol 1 with acetone 2 into solketal 3 
catalysts decrease in the series AL1 > AL2 > AL3 $>$ AL4 with the destroy of the octahedron sheet of the catalyst clay sunder the effect of the acid activation.

The acid activated clays showed a high catalytic activity for the reaction of acetalization of acetone with glycerol, solvent-free, under autogenous pressure with a full selectivity respect to the desired product solketal with yield reached $95 \%$ and glycerol conversion reaching up to $89 \%$. The mechanism proposed in this study gives an approach on the interaction between the reagents and the acid activated clay and shows the role of the catalytic surface in the selectivity of solketal production. Therefore, the acid activated clays of Maghnite were efficient and an environmentally friendly alternative route for the conversion of glycerol to solketal and other useful for the future biomass utilization.

\section{Acknowledgements}

Authors wish to acknowledge Algeria Ministry of Higher Education, University of Doctor of Moulay Tahar Saida of Algeria, and Tunisia Ministry of Higher Education and Scientific Research and the National Center of Materials Sciences of Tunisia for providing financial supporting.

\section{References}

[1] Nanda, S., Azargohar, R., Dalai, A.K., Kozinski, J.A. (2015). An Assessment on the Sustainability of Lignocellulosic Biomass for Biorefining. Renewable and Sustainable Energy Cs, 50: 925-941.

[2] Mota, C.J.A., da Silva, C.X.A., Rosenbach, N., Costa, J.J., da Silva, F. (2010). Glycerin Derivatives as Fuel Additives: The Addition of Glycerol/Acetone Ketal (Solketal) in Gasolines. Energy Fuels, 24: 2733-2736.

[3] Maximov, A.L. Nekhaev, A.I., Ramazanov, D.N. (2015). Ethers and Acetals, Promising Petrochemicals from Renewable Sources. $\mathrm{Pe}$ troleum Chemistry, 55: 3-24.

[4] Huang, Z.W., Cui, F., Xue, J.J., Zuo, J.L., Chen, J., Xia, C.G. (2012). Cu/SiO 2 Catalysts Prepared by Homo- and Heterogeneous Deposition-Precipitation Methods: Texture, Structure, and Catalytic Performance in the Hydrogenolysis of Glycerol to 1,2-Propanediol. Catalysis Today, 183: 42-51.

[5] Brett, G.L., He, Q., Hammond, C., Miedziak, P.J., Dimitratos, N., Sankar, M., Herzing, A.A., Conte, M., Lopez-Sanchez, J.A., Kiely, C.J., Knight, D.W., Taylor, S.H., Hutchings, G.J. (2011). Selective Oxidation of Glycerol by
Highly Active Bimetallic Catalysts at Ambient Temperature under Base-Free Conditions. Angewandte Chemie International Edition, 50: 10136-10139.

[6] Ezhova, N.N., Korosteleva, I.G., Kolesnichenko, N.V., Kuz'min, A.E., Khadzhiev, S.N., Vasil'eva, M.A., Voronina, Z.D. (2012).Glycerol Carboxylation to Glycerol Carbonate in the Presence of Rhodium Complexes with Phosphine Ligands. Petroleum Chemistry, 52(2): 91-96.

[7] Liu, J., Daoutidis, P., Yang, B. (2016). Process Design and Optimization for Etherification of Glycerol with Isobutene. Chemical Engineering Science, 144: 326-335.

[8] Ilham, Z., Saka. S. (2016). Esterification of Glycerol from Biodiesel Production to Glycerol Carbonate in Non Catalytic Supercritical Dimethyl Carbonate. Springer Plus, 5: 923928.

[9] Deutsch, J., Martin, A., Lieske, H. (2007). Investigations on Heterogeneously Catalyzed Condensations of Glycerol to Cyclic Acetals. Journal of Catalysis, 245: 428-435.

[10] Vicente, G., Melero, J.A., Morales, G., Paniagua, M., Martin, E. (2010). Acetalisation of Bio-Glycerol with Acetone to Produce Solketal over Sulfonic Mesostructured Silicas. Green Chemistry, 12: 899-907.

[11] Agirre, I., Güemez, M.B., Ugarte, A., Requies, J., Barrio, V.L., Cambra, J.F., Arias, P.L. (2013). Glycerol Acetals as Diesel Additives: Kinetic Study of the Reaction Between Glycerol and Acetaldehyde. Fuel Processing Technology, 116: 182-188.

[12] Fife, T.H., Jao, L.K. (1965). Substituent Effects in Acetal Hydrolysis. Journal of Organic Chemistry, 30: 1492-1495.

[13] Gopinath, R., Haque, S.J., Patel, B.K. (2002). Tetrabutylammonium Tribromide (TBATB) as an Efficient Generator of $\mathrm{HBr}$ for an Efficient Chemoselective Reagent for Acetalization of Carbonyl Compounds. Journal of Organic Chemistry, 67: 5842-5845.

[14] Mallesham, B., Sudarsanam, P., Raju, G., Reddy, B.M. (2013). Design of Highly Efficient $\mathrm{Mo}$ and W-promoted $\mathrm{SnO}_{2}$ Solid Acids for Heterogeneous Catalysis: Acetalization of Bio-Glycerol. Green Chemistry, 15: 478-489.

[15] Khayoon, M.S., Hameed, B.H. (2013). Solventless Acetalization of Glycerol with Acetone to Fuel Oxygenates over Ni-Zr Supported on Mesoporous Activated Carbon Catalyst. Applied Catalysis A: General, 464465: 191-199.

[16] Ferreira, P., Fonseca, I.M., Ramos, A.M., Vital, J., Castanheiro, J.E. (2010). Valorisation of Glycerol by Condensation with Acetone 
over Silica-Included Heteropolyacids. Applied Catalysis B: Environmental, 98: 94-99.

[17] Li, L., Korányi, T.I., Sels, B.F., Pescarmona, P.P. (2012). Highly-Efficient Conversion of Glycerol to Solketal over Heterogeneous Lewis Acid Catalysts. Green Chemistry, 14: 1611-1619.

[18] Nanda, M.R., Yuan, Z., Qin, W., Ghaziaskar, H.S., Poirier, M.A., Xu, C.C. (2014). A New Continuous-Flow Process for Catalytic Conversion of Glycerol to Oxygenated Fuel Additive: Catalyst Screening. Applied Energy, 123: 75-81.

[19] Zhang, S., Zhao, Z., Ao, Y. (2015). Design of Highly Efficient Zn-, Cu-, Ni- and Copromoted $\mathrm{M}-\mathrm{AlPO}_{4}$ Solid Acids: The Acetalization of Glycerol with Acetone. Applied Catalysis A: General, 496: 32-39.

[20] Kapkowski, M., Ambrozkiewicz, W., Siudyga, T., Sitko, R., Szade, J., Klimontko, J., Balin, K., Lelatko, J., Polanski, J. (2017). Nano Silica and Molybdenum Supported Re, Rh, Ru or Ir Nanoparticles for Selective Solvent-Free Glycerol Conversion to Cyclic Acetals with Propanone and Butanone under Mild Conditions. Applied Catalysis B: Environmental, 202: 335-345.

[21] Besbes, N., Hadji, D., Mostéfai, A., Rahmouni, A., Srasra, E., Efrit, M.L. (2012). Experimental and Theoretical Investigation on the Catalytic Acetalyzation of Carbonyl Aldehydes over Acid Activated Clay: Mechanistic Study. Journal of the Tunisian Chemical Society, 14: 39-46.

[22] Hagui, W., Mostefai, A., Rahmouni, A., Efrit, M.L., Srasra, E., Besbes, N. (2015). A Green Transformation of Ketones into Dioxolanes by Tunisian Acid Activated Clay Solvent Free: Experimental and Theoretical Studies. Journal of the Tunisian Chemical Society, 17: 1-9.

[23] Mnasri, S., Besbes, N., Frini-Srasra, N., Srasra, E. (2012). Etude De L'activité Catalytique des Argiles Pontées Aluminium, Zirconium et Cérium dans la Synthèse du 2,2Diméthyl-1,3-Dioxolane. Comptes Rendus Chimie, 15(4): 437-434.
[24] Kherroub, D., Belbachir, M., Lamouri, S., Bouhadjar, L., Chikh, K. (2018). Catalytic Activity of Maghnite-H+ in the Synthesis of Polyphenylmethylsiloxane under Mild and Solvent-free Conditions. Periodica Polytechnica Chemical Engineering. 62(2), pp. 195201.

[25] Kherroub, D., Belbachir, M., Lamouri, S. (2018). Green Polymerization of Hexadecamethylcyclooctasiloxane Using an Algerian Proton Exchanged Clay Called Maghnite-H+, Bulletin of Chemical Reaction Engineering \& Catalysis. 13(1), pp. 36-46,

[26] Ayari, F., Srasra E., Ayadi, M.T. (2007). Removal of Lead, Zinc and Nickel Using Sodium Bentonite Activated Clay. Asian Journal of Chemistry, 19: 3325-3339.

[27] Bergaya, F., Vayer, M. (1997). CEC of Clays: Measurement by Adsorption of a CopperEthylendiamine Complex. Applied Clay Science, 12: 275-280.

[28] Hamdi, N., Srasra, E. (2008). Interaction of Aqueous Acidic-Fluoride Waste with Tunisian Soil. Clays and Clay Minerals, 56: 259-271.

[29] Srasra, E., Ayedi, T.M. (2000). Textural Properties of Acid Activated Glauconite. Applied Clay Science, 17: 71-84.

[30] Srasra, E., Bergaya, F., Fripiat, J. (1994). Infrared Spectroscopy Study of Tetrehedral and Octahedral Substitutions in an Interstratified Illite-Smectite Clay. Clay and Clay Minerals, 42(3): 237-241.

[31] Srasra, E., Bergaya, F., Van Damme, H., Ariguib, N.K. (1989). Surface Properties of an Activated Bentonite-Decolorisation of RapeSeed Oils. Applied Clay Science, 4: 411-421.

[32] Burauer, S., Deming, L.S., Deming, E.W., Teller, E. (1940). On a Theory of the van der Waals Adsorption of Gases. Journal of the American Chemical Society, 62: 1723-1732.

[33] Gregg, S.H., Sing, K.S.W. (1982). Adsorption Surface Area and Porosity. Academic Press, London, 313

[34] Marton, G.I., Iancu, P., Plesu, V., Marton, A., Soriga, S.G. (2015). Sloketal- a Quantum Mecanics Study of the Reaction Mechanism of Ketalistion. Revista de Chimie-Bucharest, 66(5): 750-753. 